\title{
SOBRE GASPAR BECERRA EN ROMA. LA CAPILLA DE CONSTANTINO DEL CASTILLO EN LA IGLESIA DE SANTIAGO DE LOS ESPAÑOLES
}

\author{
POR \\ GONZALO REDÍN MICHAUS
}

Poco es lo que se sabe sobre la estancia de Gaspar Becerra en Roma, que hasta ahora se documentaba gracias a su presencia en las reuniones de la congregación de San Lucas, primero en 1544 y luego en 1550, y a la realización, entre este último año y 1551 , de una custodia para la iglesia de Santiago de los Españoles. Ya en diciembre de 1557 el andaluz se encontraba en Burgos, por lo que pasó al menos trece años trabajando en la ciudad eterna ${ }^{~}$. Aportamos aquí el contrato que Gaspar Becerra acordó con Constantino del Castillo para realizar su capilla, hoy destruida, en la iglesia de Santiago de los Españoles, cuya reconstrucción y análisis nos permiten concretar la formación y el estilo del andaluz, así como sus conexiones con el artista piacentino Giulio Mazzoni, quien, como corrobora un documento que aquí presentamos, acabó la capilla empezada por Becerra. Vaga.

Palabras clave: Manierismo. Roma. Santiago de los Españoles. Becerra. Mazzoni. Volterra. Perin del

Until now, Gaspar Becerra's stay in Rome was documented only thanks to his recorded presence at the San Lucas meetings of 1544 and 1550, and the execution of a monstrance for the church of Saint James of the Spaniards between 1550 and 1551. By December 1557 the Andalucian artist was in Burgos, thereby indicating that he spent at least thirteen years in the Eternal City. Here, the author presents the contract between Becerra and Constantino del Castillo for his chapel, today destroyed, in the church of Saint James of the Spaniards. In reconstructing and analyzing this chapel, Becerra's formation and style are clarified, as are his contacts with the artist from Piacenza, Giulio Mazzoni who, as demonstrated by a document, terminated the chapel.

Key words: Manierism. Roma. Santiago de los Españoles. Becerra. Mazzoni. Volterra. Perin del Vaga.

* Este trabajo ha sido realizado gracias una beca concedida por la Fundación del Instituto de Crédito Oficial (I.C.O.) entre marzo de 1998 y enero del 2000, para la realización de mi Tesis doctoral Gaspar Becerra y los pintores españoles en Roma 1527-1568, y ha podido ser finalizado gracias a mi actual condición de becario de la Escuela Española de Historia y Arqueología del C.S.I.C. en Roma. Agradezco la colaboración de todo el personal del Archivio Capitolino, de la Doctora Marica Mercali (Museo de Castel Sant'Angelo), del Padre Mario di Iani (Nostra Signora del Cuore), y, especialmente, de Monseñor José Luis Fernández Novalín y el padre Mariano Sanz, Rector y Vicerrector del Colegio Español en Roma, por permitirme el acceso al Archivo de la Obra Pía, cuya bibliotecaria, María Jesús Della Grana González, me ha sido de gran ayuda.

${ }^{1}$ Ceán Bermúdez, A.: Diccionario histórico de los más ilustres profesores de las bellas artes en España, vol. I, Madrid, 1800, p. 108. Vasari G.: Le vite. Ediciones de 1550 y 1568. Texto a cargo de Bettani, R. y Barocchi, P., vol. V, 1984, Florencia, p. 544 y vol. VI, 1987, Florencia, p. 388. Sobre Becerra en la todavía compañáa de San Lucas, véase Martínez de la Peña, D.: «Artistas españoles en la Academia de San Lucas», Archivo Español de Arte, (A.E.A.), vol. XLI, n. ${ }^{\circ} 163,1968$, pp. 293-313 y Leproux, G. M.: «La corporation romaine des peintres et autres de 1548 a 1574 », Bibliothèque de l'École des chartes, París, 1991, n. ${ }^{\circ}$. 149, pp. 293-349. Sobre Becerra en Burgos: Barrón, A. y Ruiz de la Cuesta, M. P.: «Notas sobre el retablo de Santa Clara de Briviesca», Archivo Español de Arte (A.E.A.), n. ${ }^{\circ} 279,1997$, pp. $255-269$.

$A E A, \mathrm{LXXV}, 2002,298$, pp. 129 a 144 


\section{La Custodia y el monumento de Semana Santa para Santiago de los Españoles en Roma}

La iglesia de Santiago agrupaba a los personajes más notables de la colonia castellana en Roma, y por tanto, era un importante foco de actividad para los artistas españoles en la ciudad. Aramburu ha publicado algunos pagos que recibió Becerra en junio y agosto de 1551 por la ejecución de una «custodia o tabernáculo» (en la contabilidad es citada de ambas maneras) para el altar mayor de la iglesia, pero una atenta revisión de los documentos revela que en realidad venía siendo pagada ya desde septiembre de $1550^{2}$. En las cuentas de Santiago hay también varias partidas destinadas al dorado y montaje de la custodia, en las que no es citado Becerra, pero sí su criado y tal vez sobrino Francisco ${ }^{3}$, que nos sirven para hacernos una idea de su forma: en febrero de 1551 se pagaban cuatro escudos «... para las quatro fenestras del tabernáculo ...», lo que nos indica que el mismo, o al menos una de sus partes, seguramente el sagrario, se componía de cuatro lados. Una custodia que coincide con la descrita, con un peso de seis libras y dos onzas, aparece ya en sendos inventarios de 1569 y 1586 ; si éste es el tabernáculo construido por Becerra (pues es improbable que se hubieran construido dos entre 1551 y 1569 ), podemos encontrarlo con el mismo peso en sucesivos inventarios hasta 1718 , año en el que se registra un tabernáculo dorado, dividido en cuatro piezas, cuyo peso no es especificado $^{4}$. Después de esta fecha se pierde el rastro de la custodia, probablemente fundida para dar material a una nueva y barroca, que fue robada en $1741^{5}$. Debió gustar el trabajo del andaluz, porque en marzo de 1554 se le pagaban «... doce escudos y un julio a buen cuento por lo que pintó en los arcos del monumento y por las ymagines que hizo de dionisio y centurio»; el monumento es el que se construía con todo boato para la Semana Santa. Seguramente estas imágenes eran las dos estatuas por las que, junto con la madera empleada en el monumento, recibió ocho escudos de oro en abril del mismo año ${ }^{6}$.

\section{La Capilla «del Castillo» en Santiago de los Españoles}

En 1551 Constantino del Castillo, deán de Cuenca, arcediano de Játiva y refrendario pontificio, fundó y dotó una capilla dedicada a la Asunción de María en la iglesia de Santiago de los Españoles en Roma ${ }^{7}$. La capilla, primera del lado de la epístola, fue alterada en 1878 y destruida entre 1938 y 1940, cuando fue abatida la fachada y el tramo del edificio adyacente a la Via della Sapienza, debido a las obras que transformaron esta calle en el actual Corso Rinascimento ${ }^{8}$.

\footnotetext{
${ }^{2}$ Los pagos de la custodia en Archivo Obra Pía (A.O.P.) 521. Camerlengo de Santiago, I550, ff. 60 y 62, septiembre A.O.P. 522. Camerlengo de Santiago, 1551: f. 53 v., febrero, ff. 56 y 56 v., junio, y f. 58 , agosto (los de junio y agosto fueron ya publicados por Aramburu).

${ }^{3}$ Se pagan a «Francisco, criado de Becerra» 5 escudos de oro en junio de 1551. A.O.P., Camerlengo de Santiago, 522, 1551. Un Francisco Becerra, sobrino de Gaspar, es citado en el testamento de su mujer, Paula Velázquez. Arias Martínez, M.: «Gaspar Becerra escultor o tracista», A..E.A, 283, 1998, p. 280.

${ }^{4}$ Por lo que respecta a los inventarios: Inventarios de la sacristía e iglesia, 1569 y 1586. A.O.P. 1164 y Libro Maestro de la iglesia, 1718 A.O.P. 402

${ }^{5}$ Sobre ésta, véase Russo, F.: Nostra Signora del Cuore, Roma, 1969, p. 54.

${ }^{6}$ A.O.P. 525, Camerlengo de Santiago, marzo, f. 56 v. y abril, f. 59. Que fueran estatuas lo indica, además, la distinción que se hace entre las mismas y lo pintado en los arcos del monumento.

${ }^{7}$ Fernández Alonso, J.: «La iglesia de Santiago de los españoles en Roma en el siglo XVI», Anthologica Annua, VI, 1958 pp. 9-122, en concreto p. 72 .

${ }^{8}$ La primera capilla del lado de la epístola fue destruida para construir una escalera, mientras que la de Del Castillo fue dividida en dos niveles, como almacén y sacristía. Archivio di Nostra Signora del Cuore, Libro della ricostruzione 1878 1882 .
}

$A E A, \mathrm{LXXV}, 2002,298$, pp. 129 a 144 
El 28 de agosto de 1553 Gaspar Becerra acordó con Constantino del Castillo (gobernador de Santiago ese año) la ejecución de su capilla del modo siguiente (Doc. 1): El andaluz debía hacer un cuadro para el altar pintado al óleo sobre tabla representando la Asunción de la Virgen acompañada por los doce apóstoles; el marco de la pintura se haría de estuco, dorado y entallado. Encima de este cuadro, en la luneta, debía ser pintada al fresco, dentro de un círculo (con el marco también estucado y dorado), la Santísima Trinidad coronando a la Virgen, todo siguiendo un dibujo del maestro que mostraba también el arco con las pilastras, que, como la cornisa de travertino, serían doradas y entalladas. En las enjutas de dicho arco, encima del arquitrabe, pintados al fresco, San Gabriel y la Virgen representarían la Anunciación, acompañada del Espíritu Santo, y entre ambos se dispondrían las armas en estuco de Constantino del Castillo con su epitafio. Sobre el arco se dispondría otro cuadro, que representaría el Descenso de Cristo al Limbo, pintado también al fresco, sobre el que debían colocarse tres estatuas de estuco. En el paño de la bóveda inmediato al altar se pintaría, siempre al fresco, la historia de la Invención de la Vera Cruz en el momento en el que Santa Elena la muestra a Constantino emperador, y en el contrario Constantino del Castillo, acompañado de algunas doncellas a las que había dotado para casarse.

Las capillas de la iglesia de Santiago son detalladamente descritas en un manuscrito anónimo de 1628 , lo que nos permite constatar que el aspecto de la capilla Del Castillo era notablemente diferente a cuanto Becerra había previsto en el contrato ${ }^{9}$. De hecho, se repite sólo la disposición del cuadro en el altar con un tondo encima, mientras que las diferencias son muchas: no se menciona la pintura al fresco de la Anunciación y el escudo que debía situarse entre la figura del ángel y María se trasladó al exterior de la capilla, donde era sujetado por dos estatuas de estuco (y no tres como pensó Becerra), situadas sobre el frontón que cubría el fresco del Descenso al Limbo, cuyo marco era sostenido por dos estatuas no mencionadas en el proyecto del andaluz. Lo cierto es que estas esculturas que flanqueaban la pintura no aparecen en la fotografía que muestra la capilla antes de ser destruida (fig. 1), por lo que el fresco fue trasladado desde su original emplazamiento en el arco exterior de la capilla, al interior de la misma, como evidencia la fotografía y un grabado que muestra el interior de la iglesia, en el que es visible todavía un gran cuadro sostenido por dos estatuas sobre el arco externo de la capilla Del Castillo, primera de la nave derecha ${ }^{10}$. Por lo que respecta a la bóveda, sólo se hace referencia a la Invención de la Cruz por Santa Elena, de manera que el fresco del donante acompañado por las doncellas no fue pintado. La descripción de la capilla añade otros datos interesantes, como la atribución del cuadro de la Asunción a «Castello fiammingo», o las atribuciones a Perín del Vaga del fresco de la bóveda y los cuatro santos pintados a los lados del altar; finalmente, se cita como autor del fresco del Descenso al Limbo a un tal «Niuno, pittore spagnolo», artista desconocido cuyo nombre, escrito confusamente, requiere una explicación. La penúltima letra de su nombre está tachada,

\footnotetext{
${ }^{9}$ Biblioteca Romana (Archivio Storico Capitolino). Leg. 12449. Fechado en la contraportada, 1628. Sin foliar. Este manuscrito parece ser el mismo citado, sin concretar su ubicación, por Romano, P. y Partini, P.: Piazza Navona, Roma, 1934, p. 34. La descripción dice así: «... La prima capella con balaustrata di marmo e balaustri di metallo é riguardevole per gli stucchi e per le pitture a' fresco ha nell'altare un quadro a olio della vergine Assunta del Castello fiamengo, con frontespicio aperto sopra due mensule e dentro al frontespicio un ovato tenuto da due angeli di stucco dove é dipinto ne fianchi dell'altare quattro santi figure in piedi, fra questi S.Gerolamo, S.Alfonso pitture tutte á fresco di Pierino, nell'arco della capella due figure di stucco che tengono due festoni con un ovato in mezzo, entro al quale si legge (...) sopra l'arco nella facciata in un gran quadro con due statue di stucco dalle bande in atto di sostenere il quadro dipinto é Christo che esce dal Limbo, opera a' fresco famosa del Niuno (sic) pittore spagnolo. Sopra il quadro un frontespicio aperto di stucco coll'arme in mezzo del fondatore della cappella tenuta da due statue. Nel triangolo della volta l'inventione della Croce a' fresco di Perín. Tutte queste pitture, come ancora il quadro, il resto dell'altare, son' ornati con fogliami et altri lavori di stucco disegni di Perín.»

${ }^{10} \mathrm{El}$ grabado fue dibujado por Canevari e inciso por Vasconi.
}

AEA, LXXV, 2002, 298, pp. 129 a 144 

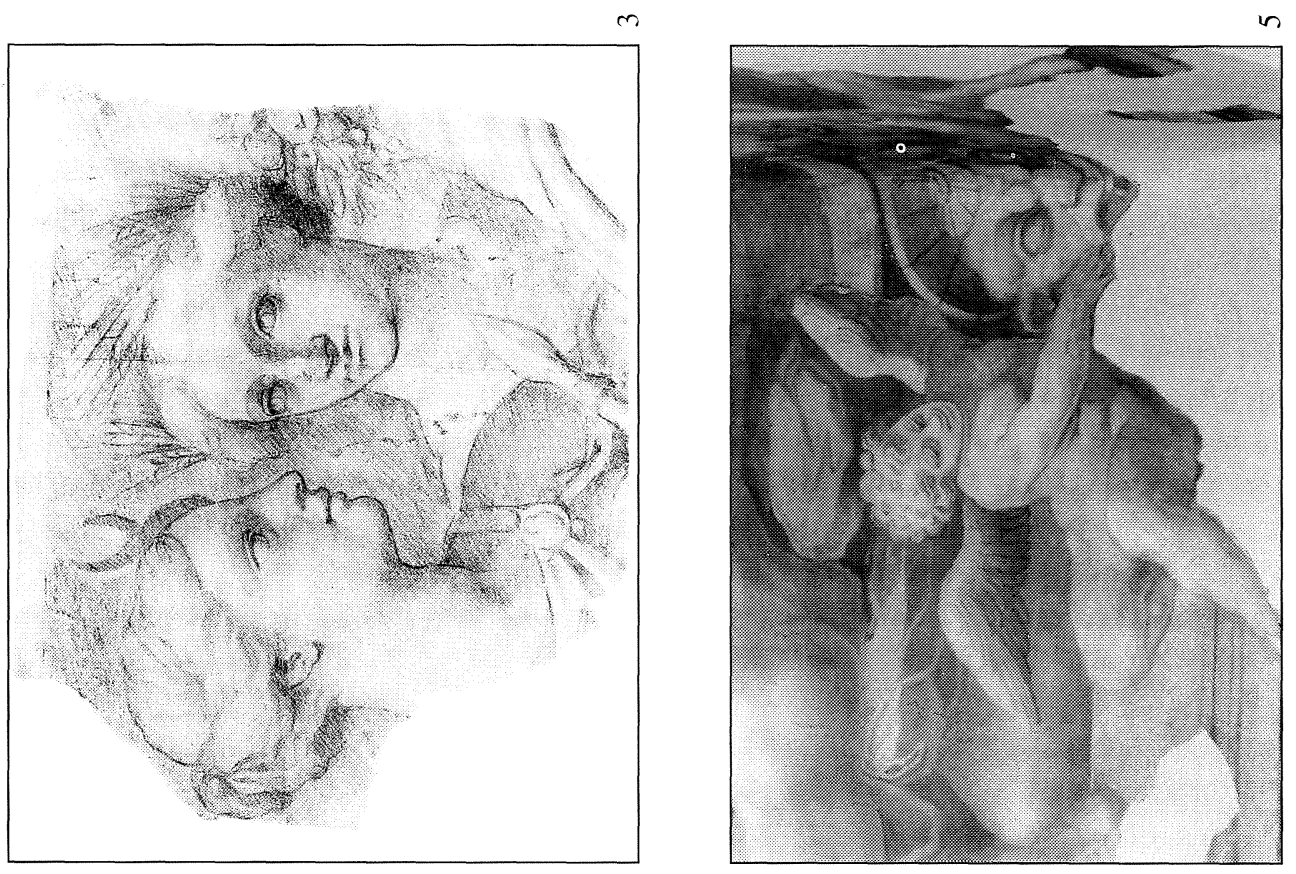

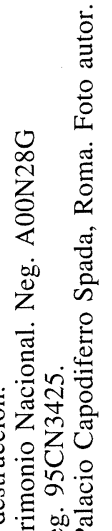

क ज芯。

ชั एं

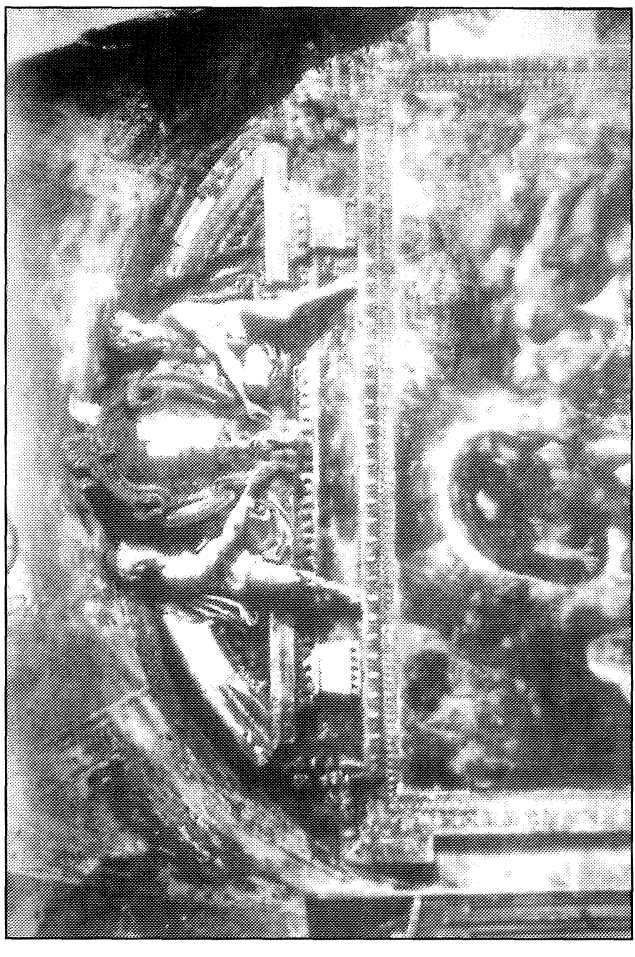

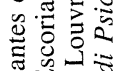

สี س둬

焉密

Uึ ฮึ

$\approx$

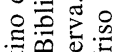

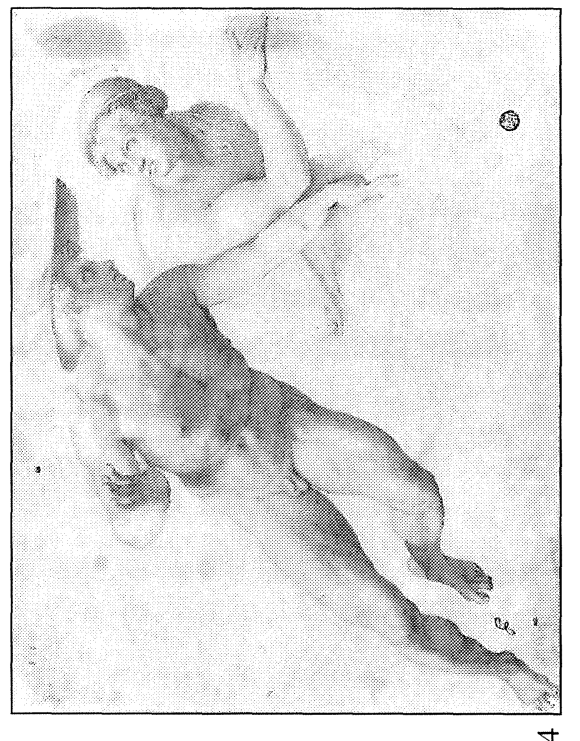

ज्ञ

ठี

䑩

플

कृष

퓰

ชळ

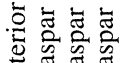

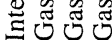

一 $m$ t $n$

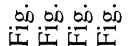


de modo que se puede leer Niuo, Niuno, Niuto e incluso, en una lectura apresurada, Muto; probablemente debido a esta última interpretación se ha identificado a Juan Fernández de Navarrete «El Mudo» (muto en italiano), como autor de la pintura, sin que se especificara nunca la razón ${ }^{\prime \prime}$. Las diferencias existentes entre la capilla contratada y la ejecutada, un documento inédito que demuestra la participación del pintor italiano Giulio Mazzoni en la misma, y las atribuciones que se hacen en el manuscrito (especialmente las referidas a Perín del Vaga), plantean una serie de cuestiones sobre la intervención de Gaspar Becerra en el conjunto que vamos a intentar resolver a continuación.

Según el testimonio del pintor Pietro Pisa, Giulio Mazzoni (llevado a juicio por sus colegas de la compañía de San Lucas por no pagar las cuotas anuales ni su ingreso en la misma), terminó la capilla comenzada por Becerra en Santiago de los españoles ${ }^{12}$. Efectivamente, el español no pudo acabar el trabajo en el plazo de un año estipulado en el contrato, de manera que Del Castillo pudo utilizar la cláusula que en tal caso le permitía mandarlo terminar «... a otro maestro que él quisiere a espesa y daño del dicho Gaspar Becerra excepto enfermedad o muerte...», lo que explica las grandes diferencias existentes entre la decoración ideada por Becerra y su realización definitiva. El maestro elegido fue Giulio Mazzoni, que continuó y acabó el encargo alterando el proyecto inicial, lo que prueba un pago de 25 escudos recibido en julio de 1557 por lo que había pintado en la capilla ${ }^{13} \mathrm{y}$ el aspecto definitivo de la misma, que podemos comprobar parcialmente gracias a la citada fotografía (fig. 1) que muestra el cuadro del Descenso al Limbo y los estucos que le acompañaban.

Que Mazzoni fuera elegido para continuar el proyecto no fue una decisión casual, pues su estilo era similar al de Becerra, del que además era amigo, como leemos en una carta que Felipe II dirigió en junio de 1567 a Luis de Requesens, embajador en Roma. En ella se requiere, a petición del andaluz, la contratación de dos pintores que ayudaran al baecetano en España, para cuya elección se debía consultar con Giulio Mazzoni y Siciolante de Sermoneta «... que el dicho Becerra dice que son sus amigos ... y ase de tener en cuenta que no vengan (los pintores) si no es con pareszer destos dichos, porque se podría herrar de otra manera» ${ }^{14}$. El proyecto de Becerra para la capilla Del Castillo recordaba la Sala Regia iniciada por Perín del Vaga en el Vaticano y la obra de Mazzoni en el Palacio Capodiferro. Todo parece indicar que el baecetano trabajó hacia 1550 en este palacio, donde coincidió con Sermoneta y el piacentino: Mazzoni dirigía junto con el español Diego de Fiandra uno de los equipos que se encargaban de la decoración del edificio, mientras que el otro equipo estaba dirigido por Tomaso

\footnotetext{
"Una nota anónima en Bolletino d'Arte que señala la adquisición de la pintura, la atribuye, sin aducir razón alguna, a Navarrete. Costanzi, Cecchelli y Russo repiten la atribución. Bolletino d'Arte, vol. IX, 1929, p.268. Costanzi, E.: «Vicende di una antica chiesa degli spagnoli a Roma», L Tllustrazione vaticana, 15 septiembre 1935, pp. 956-957p. 956. Cecchelli, C.: «Una Chiesa insigne sul nuovo corso rinascimento, Roma, XIV, 1936 p. 330 . Russo op. cit., p. 2.

${ }^{12}$ Mazzoni afirma que no es pintor, por lo que no debe cumplir con la compañía, pero otros pintores aseguran haberlo visto pintando, y Pisa garantiza que acabó la capilla comenzada por Becerra. Leproux, G. M.: «Les peintres romans devant le tribunal du senateur. 1544-1564», Monuments et mémoires. Fondation Eugène Piot, pp. 115-134, en concreto pp. 115116.

${ }^{13}$ A.S.C. Archivio Urbano. Sección I. Leg. 269, f. 288 v. Biagio de Casarruvias. 5 julio 1557. Giulio Piacentino recibe 25 scudi como parte del pago de una pintura en la capilla de Constantino Del Castillo en Santiago de los Españoles. « (...) Magister Julius Pla(ce)n(tinus) pictor confessus fuit habuisse et recepisse, prone habuit in presentia mei notarii (...) a Constantino del Castello decano Conchense per manus dicti Baptiste Castello scuta 25 ad iulios decem pro qualibet scuto ad bonum computum et partem solutionis pretii picture capelle ipsius domini Constantini in ecclesia Sancti Jacobi Hispanorum de Urbe iuxta formam contractus de quo in actis meis de quibus XXV scutis dictus magister Julius se bene contentus vocavit quietavit promisit ... ».

${ }^{14}$ La carta, que llego a Roma el 7 de agosto, en A.S.C. Archivo Urbano. Sez. I. 857. Alfonso de Ávila, f. 277. En el mismo legajo, ff. 280-281, está el posterior contrato con Cajés y Cincinato, ya localizado en España por Martín González, J. J.: «El Alcázar de Madrid en el siglo xvi», A.E.A. 1962, p. 18. Sobre la misma trataremos en un artículo de próxima aparición en esta revistá.
} 


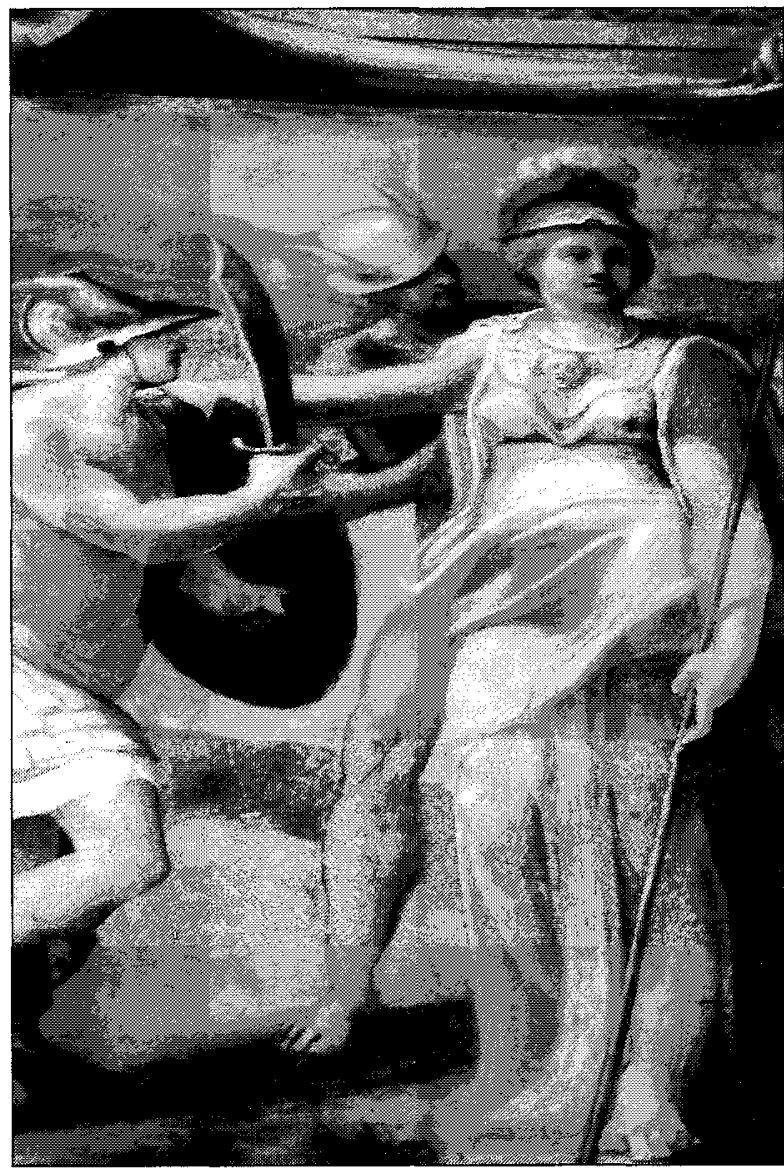

Fig. 2. Gaspar Becerra, Minerva. Detalle del friso de la Sala di Perseo del Palacio Capodiferro Spada, Roma. Foto del autor.

Boscoli y Leonardo Sormani ${ }^{15}$, con este último estaba estrechamente relacionado Becerra, pues testimonió a su favor durante la celebración de un juicio relativo a la compraventa irregular de una columna que Sormani mandó recoger, precisamente, enfrente del Palacio Capodiferro $^{16}$.

Señalar la intervención de Becerra en dicho palacio es difícil, pues fue decorado casi totalmente entre 1548 y 1550 , en sólo dos años, por lo que un gran número de artistas trabajó contemporáneamente para acabar cuanto antes su decoración ${ }^{17}$. Sin embargo, creemos reconocer la mano del andaluz en parte del friso de la Sala de Perseo: compárese la Minerva de dicho friso (fig. 2) con el dibujo de Ceres y Diana (fig. 3) o el de la misma diosa que se conservan en la Biblioteca de El Escorial, o con la Minerva que acompaña a Mercurio (fig. 4) de la colección de dibujos del Museo del Louvre ${ }^{18}$. Tal vez Becerra pintó alguno de los Putti de la Sala de Psiche (fig. 5) de dicho palacio, que pueden relacionarse con los que aparecen en el frontispicio de la Historia del Cuerpo humano (fig. 6) que Fracchia atribuye al andaluz ${ }^{19}$. Finalmente, queremos destacar como algunas de las estatuas de estuco de la Sala de Calixto (fig. 7), ejecutadas por Mazzoni y su equipo ${ }^{20}$, se relacionan claramente con el único fragmento escultórico que nos ha llegado de la capilla Del Castillo (fig. 8), una cabeza que encontramos aunque más tosca y ejecutada casi 20 años más tarde, en el retablo de Vallarta de la Bureba en Burgos (fig. 9), contratado por López de Gámiz, siempre atento a las novedades que Becerra trajo de Italia ${ }^{21}$.

\footnotetext{
${ }^{15}$ Sobre la decoración del palacio, realizada en su mayor parte entre 1548 y 1550 , véase Cannatá, R.: «Novitá su Giulio Mazzoni, Leonardo Sormani, Tommaso del Bosco e Siciolante da Sermoneta», Bolletino d'Arte, n. ${ }^{\circ}$. 70, vol. LXXVI, 1991 , pp. 87-103. Cannatà sugiere que Diego de Fiandra (Flandes), dicho español en la documentación, pueda ser el Diego Spagnolo que Francia documenta entre 1544 y 1546 en San Pedro. Cannatà, p. 103, n. 11. Francia, E.: Storia della costruzione del nuovo San Pietro. Roma, 1977, pp. 67-68.

${ }^{16}$ Bertolotti, A.: Artisti subalpini a Roma, Bologna, 1884, pp. 106-107.

${ }^{17}$ Cannatà, art. cit., p. $87-88$ e 100

${ }^{18}$ Angulo Iñiguez, D. y Pérez Sánchez, A.: A corpus of spanish drawings, 1450-1600, Londres, 1975, pp. 21-26. Pérez Sánchez, E. y Boubli, L.: Dessins Espagnols des XVI et XVII siècles. Musée du Louvre, París, 1991. Cat. ․o 2. Inv. 2763. Mercurio y Minerva.

${ }^{19}$ Fracchia, C.: «La herencia italiana de Gaspar Becerra en el retablo mayor de la Catedral de Astorga», Anuario del Departamento de Historia y Teoría del Arte (U.A.M), n. ${ }^{\circ}$ IX-X, 1997-1998, pp. 133-149, en particular p. 138.

${ }^{20}$ Cannatà, art., cit., p. 94.

${ }^{21}$ Sobre el retablo de Vallarta de Bureba, véase Barrón, A y Ruiz de la Cuesta, M. P.: «Noticias sobre Pedro López de Gámiz», Estudios Mirandeses, 12, 1992, pp. 21-71.
}

AEA, LXXV, 2002, 298, pp. 129 a 144 

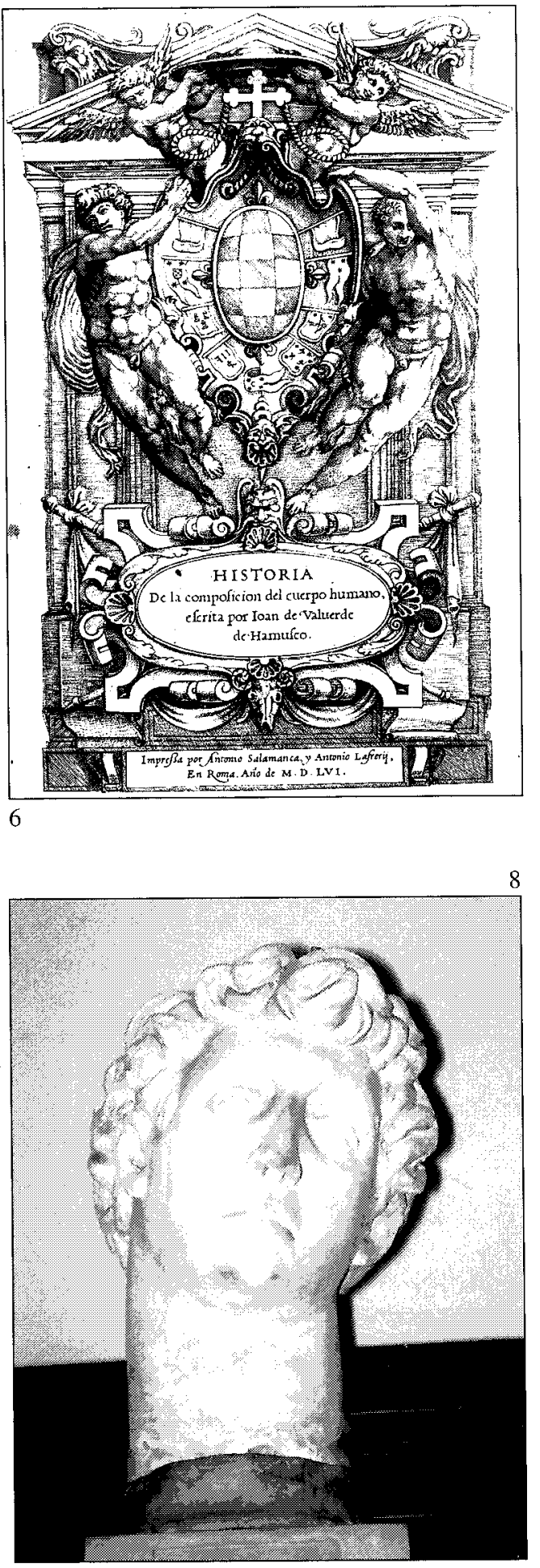

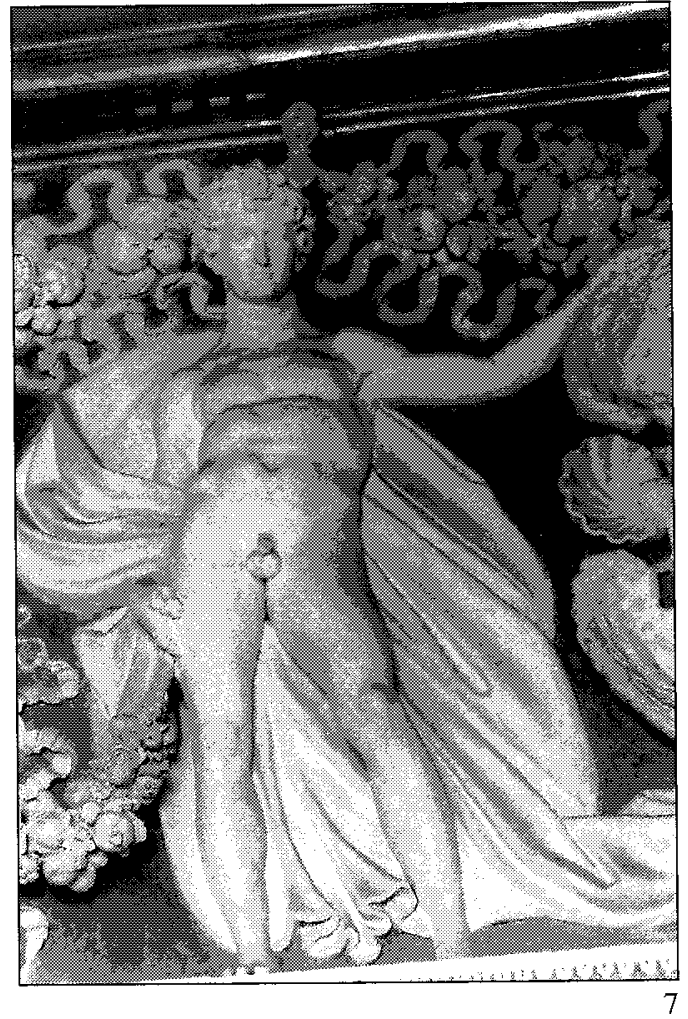

9

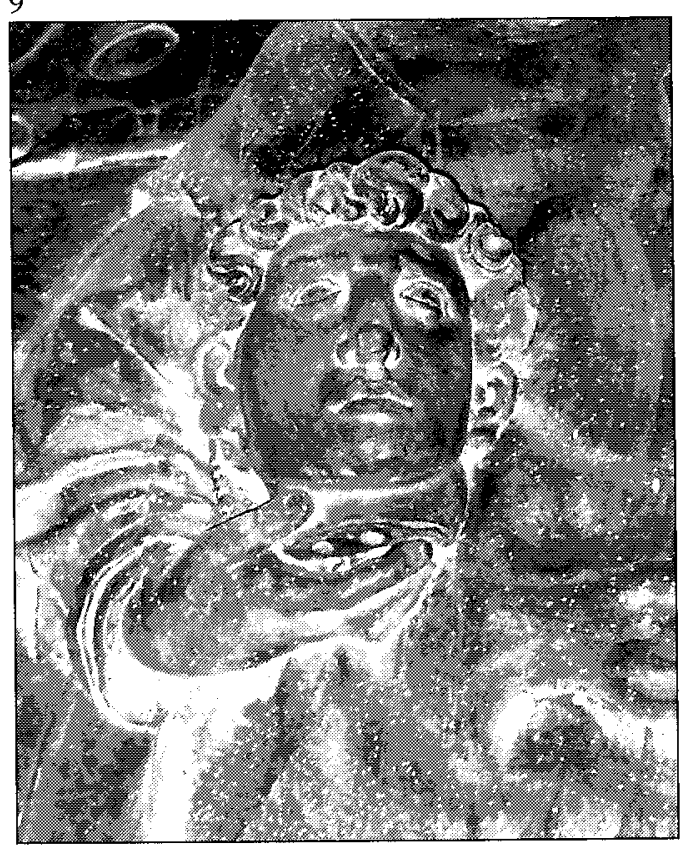

Fig. 6. Gaspar Becerra. Frontispicio de la Historia del cuerpo Humano de Juan de Valverde. Biblioteca Nacional. Fig 7. Giulio Mazzoni y taller. Detalle de la decoración de la Sala di Callisto. Palacio Capodiferro Spada. Foto autor. Fig. 8. Giulio Mazzoni. Cabeza de una de las estatuas de la capilla Del Castillo. Sacristía de Nostra Signora del Sacro Cuore (antes Santiago de los Españoles). Foto del autor.

Fig. 9. López de Gámiz. Detalle (cabeza de San Vitores) del retablo de San Miguel de la parroquia de Vallarta de Bureba (Burgos). Foto autor. 


\section{Las atribuciones a Perín del Vaga y la intervención de Mazzoni}

Volviendo a la capilla del Castillo, ya hemos dicho que la decoración ideada por Becerra se inspiraba en la decoración de la Sala Regia del Vaticano, que fue comenzada por Perín del Vaga y continuada por Daniele da Volterra tras la muerte del florentino. En la Sala trabajó seguramente por entonces Giulio Mazzoni ${ }^{22}$ que aplicó el esquema decorativo de la misma estatuas de estuco sobre los marcos de las pinturas- en el Palacio Capodiferro y en la conclusión de la capilla del Castillo. No sorprende entonces que el fresco de la Invención de la Cruz de la bóveda y la decoración en estuco sean atribuidos a Perín del Vaga en la anónima descripción de la iglesia, porque quien la escribió se dejó confundir por la afinidad que la capilla tenía con la decoración de la Sala Regia.

Se ha sugerido que la capilla fue comenzada por Perín del Vaga antes de ser concedida a Constantino del Castillo, y que, incompleta a su muerte, el encargo habría pasado a Daniele da Volterra, quien a su vez lo habría delegado a su discípulo, Gaspar Becerra ${ }^{23}$. Esta posibilidad debe ser rechazada, pues en el contrato no se menciona ninguna decoración preexistente y se afirma claramente que el español debía pintar al fresco en la bóveda la Invención de la Cruz.

El frontón y las estatuas (fig. 1) han sido atribuidos por Fracchia a Becerra ${ }^{24}$ : entre la contratación de la capilla y el pago recibido por Mazzoni pasaron más de tres años, lo que permite suponer que para entonces buena parte de la misma había sido hecha por el baecetano, estucos incluidos. Sin embargo, el hecho de que unos años más tarde el piacentino realizara en la misma iglesia la capilla Ramírez de Arellano, que debía hacerse a semejanza de la frontera capilla de Constantino del Castillo ${ }^{25}$, los numerosos cambios efectuados sobre el proyecto descrito en el contrato, y la similitud estilística que el único resto de la decoración en estuco tiene con el hacer de Mazzoni - la cabeza de una de las estatuas, que hoy vigila la sacristía de Nostra Signora del Sacro Cuore en Piazza Navona (fig. 8) - parecen indicar que el piacentino fue el autor del aparato visible en la fotografía.

\section{El fresco del «Descenso al Limbo»}

La pintura se encontraba en la iglesia de Santiago de los Españoles (Nostra Signora del Sacro Cuore a partir de 1878), hasta que en 1930 fue comprada por el Ministero della Pubblica Istruzione y trasladada a un almacén en el Museo de Castel Sant'Angelo, donde hoy se encuentra ${ }^{26}$. El cuadro representa el momento en el que Cristo, poco después de su muerte, bajó

\footnotetext{
22 Aunque no hay documentación que garantice la intervención de Mazzoni en la Sala Regia antes de 1563, Pugliatti sitúa muy convincentemente al piacentino formando parte del equipo de Daniele da Volterra que decoró parte de la sala entre 1547 y 1549. Pugliatti, T.: Giulio Mazzoni e la decorazione a Roma nella cerchia di Daniele da Volterra, Roma, 1984, pp. $187-192$

${ }^{23}$ Primero Davidson, B.: «Navarrete in Rome», Burlington Magazine, vol., CXXXV, 1079, Febrero 1993. pp. 93-96. Fracchia, art., cit., p. 141.

${ }^{24}$ Fracchia art., cit. p. 144.

${ }^{25}$ Además, al final del contrato se especificaba que el Gobernador de Santiago, Luis de Torres, se cercioraría de que la capilla hubiera sido hecha «in modo equivalente» a la de Del Castillo, de lo contrario la cantidad pagada por la obra sería menor. A.S.C. A.U. Sez I. Leg. 862.18 de agosto de 1571, ff. 312 a 314 . La capilla fue apenas empezada, porque en abril de 1572 moría Bernardino de Sandoval, ejecutor del testamento de Ramírez de Arellano, cuya voluntad recayó en el hermano de Sandoval, que el 30 de julio del mismo año pagó a Mazzoni por lo que había hecho en la capilla y contrató con el mismo la decoración de una nueva, situada al final de la nave de la epístola. A.S.C. A. U. Sez. I. 863.30 luglio 1572. F. 204-206.

${ }^{26}$ En 1930 fue vendido al Ministero della Pubblica Istruzione por 20000 liras, como se lee en una carta del 16 de Julio del mismo año dirigida a la Direzione Generale delle Belle Arti, localizada en el Archivo de la iglesia de Nostra Signora del Sacro Cuore. Serie I, busta II, fascicolo 1 I.
}

$A E A, \mathrm{LXXV}, 2002,298$, pp. 129 a 144 


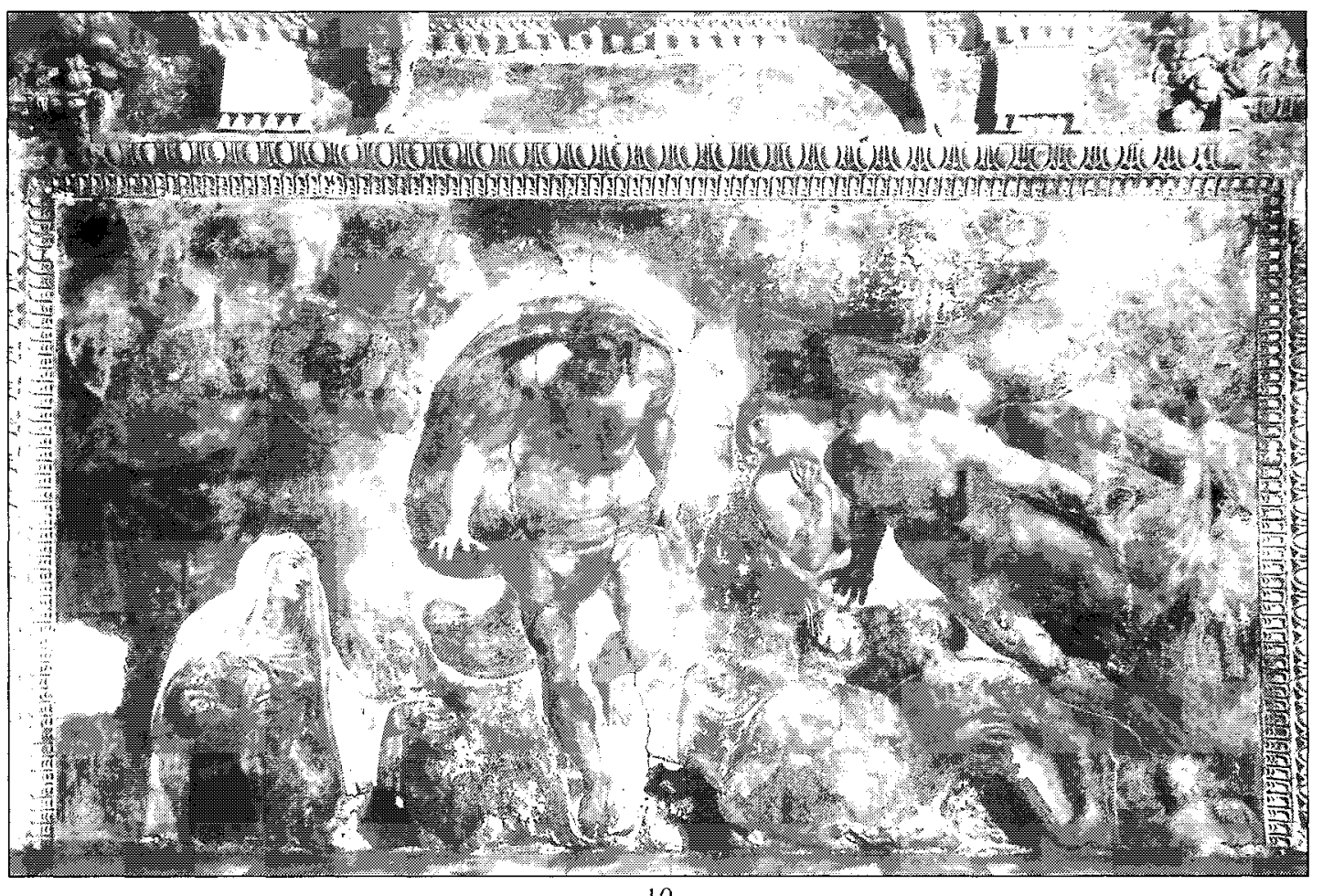

10

11

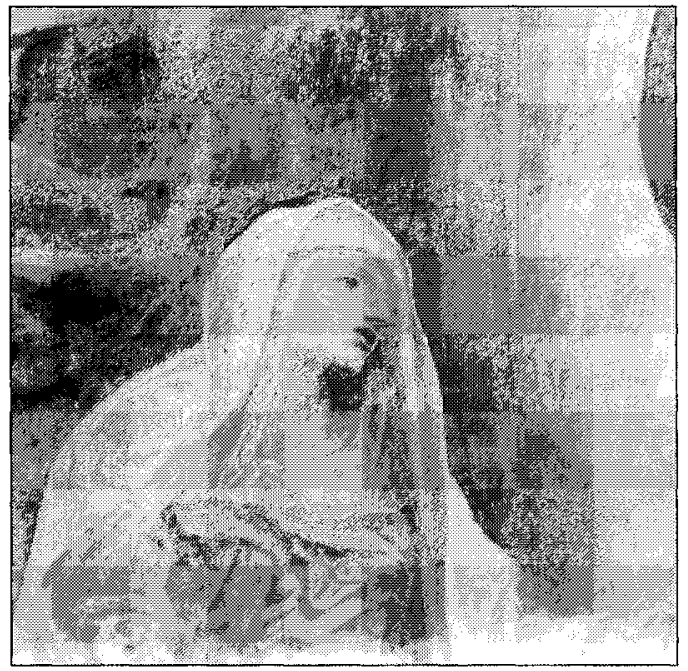

12

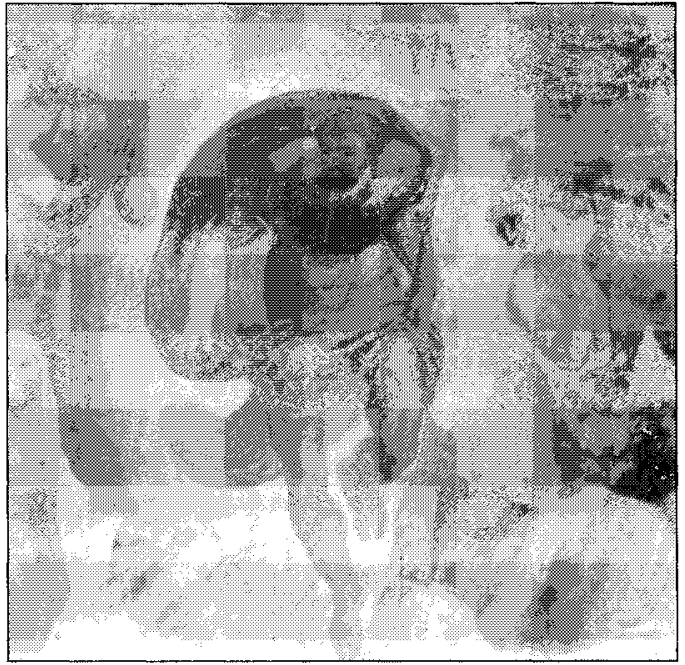

Fig. 10. Capilla de Constantino del Castillo (destruida). Descenso de Cristo al Limbo. Soprintendenza per i Beni Artistici e Storici di Roma. Neg. 20478.

Fig. 11 Gaspar Becerra. Descenso de Cristo al Limbo, detalle de María. Biblioteca del Museo Nazionale di Castel Sant'Angelo. Neg. 42412.

Fig. 12 Gaspar Becerra. Descenso de Cristo al Limbo, detalle de Cristo. Biblioteca del Museo Nazionale de Castel Sant'Angelo. Negativo 42416.

AEA, LXXV, 2002, 298, pp. 129 a 144 
al Limbo para liberar a los Justos no bautizados que allí esperaban la resurrección eterna (fig. 10) ${ }^{27}$. En este caso se insiste en la validez de la intercesión de María ante Dios, negado por los reformistas, que tampoco reconocían el valor a las reliquias, exaltado en la misma capilla con la representación de la Invención de la Cruz.

El fresco, que fue trasladado a tela, ha sufrido grandes perdidas de pintura y no ha sido restaurado recientemente ${ }^{28}$. Pese a todo, todavía se pueden apreciar los vivos colores que tuvo en la figura de la Virgen (fig. 11) y en el aura dorada (fig. 12) que rodea a Cristo. La pintura fue cortada cuando la capilla fue dividida por un falso suelo en dos niveles y ha sido erróneamente atribuida a Navarrete por Davidson, que se fundamenta para ello en las anteriores atribuciones y en la comparación con otras obras del pintor, especialmente con la que del mismo tema se conserva en El Escorial; la estudiosa atribuye también a Navarrete un espléndido dibujo conservado en la Galleria dell'Accademia en Venecia (Fig. 13) que sin duda se usó como modelo para la figura de Cristo en el fresco ${ }^{29}$. Mulcahy ha rechazado correctamente ambas atribuciones y considera la técnica de ejecución del dibujo muy cercana a los que se conservan en la biblioteca de El Escorial (fig. 3), lo que junto con la referencia documental de Leproux le permiten atribuir correctamente dibujo y fresco al

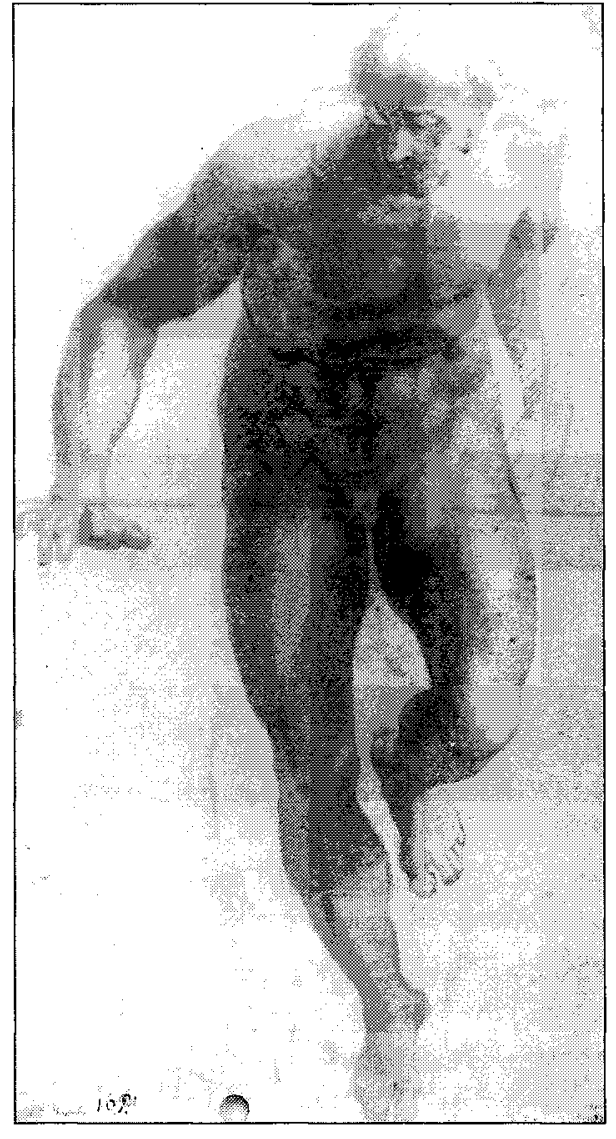

Fig. 13 Gaspar Becerra. Dibujo de Cristo. Galleria dell'Accademia di Venezia. Negativo 14659/G. andaluz ${ }^{30}$. El dibujo en cuestión fue dado a conocer por Selvatico, que lo consideró una copia hecha por Sebastiano del Piombo de una de las figuras del Juicio Final de Miguel Ángel; sin embargo, como ha señalado Prosperi, no se copia ninguna de ellas: para la estudiosa, el recorrido plano y continuo del lápiz evidencia que se trata de una copia hecha hacia fines del XVI, derivada de un modelo de Muziano, Sebastiano del Piombo, o Volterra, a concretar ${ }^{31}$. En realidad el prototipo es un dibujo conservado en el British Museum que se considera copia del que Miguel Ángel envió a Sebastiano del Piombo en Julio de 1532 y que representa también a

\footnotetext{
${ }^{27}$ Becerra prescinde de la primitiva figuración del tema: a los pies de Cristo no aparecen abatidas las puertas del infier no, ni Satanás dominado bajo la Cruz. Entre los presentes, además de Adán y Eva, padres y símbolos de la humanidad redimida, reconocemos a David, con el arpa, algunos de cuyos salmos son interpretados como predicción del descenso triunfal de Cristo; Abel, con su bastón de pastor; Moisés, sosteniendo las tablas de la ley; Abraham, con la barba blanca, y junto a David, un joven que tal vez sea su hijo Salomón. Reau, L.: Iconographie de l'art chretien, vol. II, pp. $531-537$ y vol. I, pp. 175-178.

${ }^{28}$ Fue pasado a lienzo en 1545 en el Laboratorio Restauro Vaticano. Leg. 1752.

${ }^{29}$ Davidson, art., cit., pp. 94-95. Según la estudiosa, la comparación del fresco con la pintura del mismo tema hecha por Navarrete que se conserva en El Escorial permite la atribución de la pintura romana a «El Mudo». Sobre las anteriores atribuciones a Navarrete, véase la nota 11 .

${ }^{30}$ Véase la referencia de Leproux en la nota 12. La estudiosa menciona, además, la existencia de una pequeña tabla, hoy perdida, con Cristo resucitado, que podría ser un boceto de la pintura. Mulcahy op., cit., p. 49 y 55.

${ }^{31}$ Selvatico, P.: Catalogo delle opere d'arte contente nella Sala delle Sedute della I.R.. Accademia de Venezia, Venezia, 1854. Prosperi, S.: Disegni romani, toscani e napoletani, Galleria dell'Accademia di Venezia. Milán, 1989, p. 35 .
}

$A E A, \mathrm{LXXV}, 2002,298$, pp. 129 a 144 
Cristo descendiendo al Limbo, del que se copia el brazo extendido, e, invertido, el tren inferior ${ }^{32}$.

El penoso estado del fresco hace que las anatomías carezcan del escultórico modelado del dibujo. Sin embargo, es posible ver las incisiones de la caña sobre el enlucido, que pese a los repintes (evidentes sobre todo en los brazos, pecho y vientre) demuestran que la figura de Cristo fue trazada con exactitud respecto al dibujo ${ }^{33}$. Pese a todo, se aprecian algunas diferencias: el rostro está dibujado torpemente y se evita el desnudo de Cristo cubriéndolo con un ampuloso paño de impronta perinesca, similar al que viste a los genios que sujetan el frontispicio de la edición española de la Historia del cuerpo humano de Juan de Valverde (fig. 7). Mejor conservada está la figura de la Virgen María (fig. 11), estupendamente dibujada, que depende de la pintada por Daniele da Volterra en la Asunción de la capilla Della Rovere en la iglesia de Santa Trinità dei Monti, con la que comparte el mismo tipo de rostro, ancho, con la nariz casi triangular y los párpados grandes y pesados, que encontramos en las esculturas del retablo de Astorga o los cartones de El Escorial. Entre el resto de los personajes destacan también por su mejor estado de conservación las figuras de Adán y Eva, muy similares a las de Mercurio y Minerva (fig. 4) del dibujo conservado en el Louvre, lo que nos hace pensar que pese al pago que recibió Mazzoni por pintar en la capilla, el Descenso al Limbo fue pintado en solitario por el andaluz.

\section{La formación de Becerra en Roma}

Fracchia, que atribuye a Gaspar Becerra el frontispicio de la edición española de la Historia del cuerpo humano de Juan de Valverde y una de sus láminas ${ }^{34}$, ha demostrado la influencia que Vasari y, sobre todo, Daniele da Volterra, tuvieron en la formación del andaluz. A ambos maestros se debe añadir Giulio Mazzoni, cuya estrecha relación con Becerra creemos haber demostrado. Las atribuciones de Fracchia son correctas, y se corroboran al ser cotejadas con el fresco del Descenso al Limbo. Por lo que respecta al frontispicio, se pueden comparar sus geniecillos alados con el que aparece en el cartón Ninfa y Sátiro de la Biblioteca de El Escorial; la misma afinidad formal encontramos entre los genios que soportan el escudo del frontispicio y la figura de Cristo en el fresco romano (figs. 6 y 13), o entre esta última y el Perseo, un poco torpe, que centra la bóveda del Palacio de El Pardo (fig. 14). Todos estos tipos están definidos por la marcada influencia de Daniele da Volterra, sin descuidar la influencia del Tibaldi de la Sala Paolina de Castel Sant'Angelo, que a la sinuosa caligrafía de Perín del Vaga integra la monumentalidad de Miguel Ángel. Incontestable es también la atribución a Becerra de la lámina VI de la Historia del cuerpo humano de Juan de Valverde por su similitud con la Opulencia de la «Sala dei Cento Giorni» del Palacio della Cancillería. Ambas figuras comparten la rotundidad de las alegorías del retablo de Astorga, como la Vigilancia, cuyo perfil reconocemos en la figuras de María o Eva en el fresco de Santiago.

Como es sabido, Vasari indica que Becerra pintó la luneta del Nacimiento de la Virgen en la capilla Della Rovere (fig. 15), comisionada a Daniele Ricciarelli da Volterra en la iglesia romana de Trinità dei Monti. Recientemente hemos tenido la oportunidad de ver la pintura de cerca gracias a la restauración en curso de la capilla y en nuestra opinión, la intervención de Becerra

\footnotetext{
${ }^{32}$ Sobre este dibujo, véase Perrig, A.: Michelangelo's drawings, New Haven, 1991, p. 42.

${ }^{33}$ En una carta anónima del 9 de octubre de 1929 dirigida al mismo Ministerio, se dice que el fresco había sido muy atacado por el salitre a causa de la reciente rotura de una conducción que no había sido localizada. Archivio de Nostra Signora del Cuore. Serie I. Busta II. Fascicolo 11.

${ }^{34}$ Fracchia art., cit., p. 137
} 

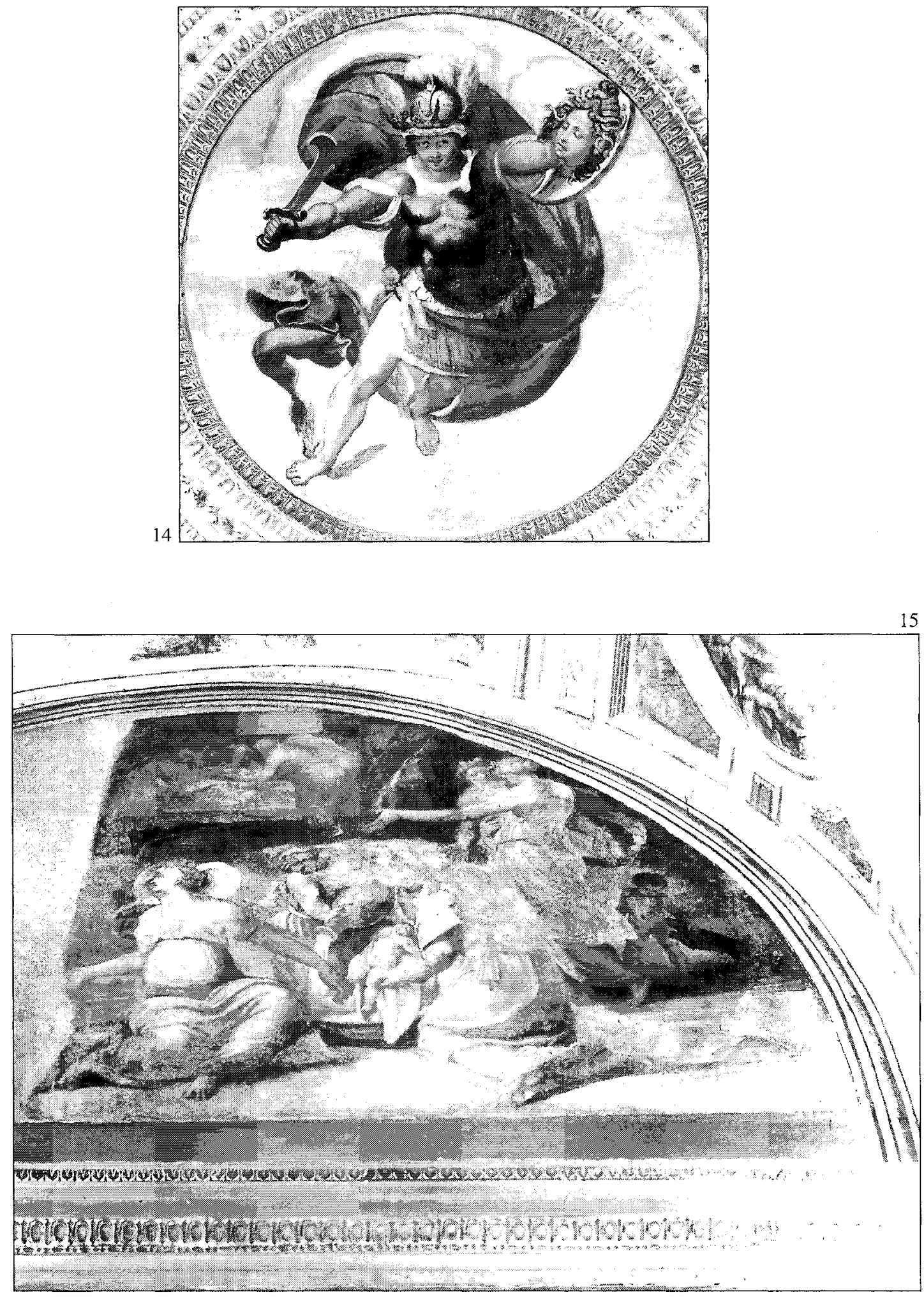

Fig. 14. Taller de Gaspar Becerra. Perseo. Fresco de la Torre de la Reina del Palacio de El Pardo. Patrimonio Nacional. Fig. 15. Gaspar Becerra y colaborador. Capilla Della Rovere, Roma, Iglesia de S. Trinità dei Monti. Soprintendenza per i Beni Artistici e Storici di Roma, neg. 162274.

$A E A$, LXXV, 2002, 298, pp. 129 a 144 
- a datar entre 1548 y su llegada a España - se limita sólo a la mujer que versa el agua y a la nodriza que le acompaña ${ }^{35}$. El resto de pintura tiene poco que ver con el estilo del español, lo que se explica por la existencia de un pequeño dibujo preparatorio para la luneta atribuido a Marco Pino que fue utilizado en la ejecución final ${ }^{36}$. Creemos que la intervención del andaluz en el fresco fue sólo parcial y que la luneta fue pintada en colaboración con otro pintor, como sucedió seguramente en el Matrimonio de la Virgen, ejecutado contemporáneamente en la misma capilla, que se atribuye convincentemente al trabajo conjunto de Marco Pino y Pellegrino Tibaldi ${ }^{37}$. Aunque se utilizó una composición de Marco Pino para el Nacimiento de la Virgen y los rostros de las figuras que adscribimos al español recuerdan mucho a los pintados por Tibaldi, ninguno de los dos italianos pintó en esta luneta, pues la técnica empleada en la misma es radicalmente opuesta a la utilizada por Tibaldi y Pino: en el fresco del andaluz los personajes son cuidadosamente pintados dentro de los límites del dibujo inciso en el enlucido, mientras que en la luneta pintada por los italianos los contornos de las figuras rara vez coinciden con las líneas incisas en el revoque. Pese a que paradójicamente la intervención de Becerra en la capilla Della Rovere no demuestra una afinidad particular con Daniele da Volterra, es indudable que el baecetano formó parte de su bottega, pues sólo allí pudo conocer una pintura, Mercurio ordena a Eneas dejar a Dido (fig. 16), de la que repetiría más tarde algunas figuras en la Historia de Perseo del Palacio de El Pardo ${ }^{38}$. Según cuenta Vasari, el cuadro fue encargado al Ricciarelli por el poeta Giovanni Della Casa, autor de El Galateo, para ser enviado a Francia; no sabemos exactamente cuándo se fecha la pintura, pero probablemente se puede datar entre el regreso del poeta a Roma desde Venecia después de junio de 1555 y su muerte en noviembre de $1556^{39}$. Parece que a la muerte de Della Casa la obra no había sido terminada, pues un cuadro inacabado de idéntico tema y atribuido a Daniele da Volterra se menciona pocos años después en el inventario de Fulvio Orsini, de manera que la pintura habría permanecido un cierto tiempo en el taller del Ricciarelli, siendo accesible exclusivamente a los más estrechos colaboradores del volterrano ${ }^{40}$. Entre ellos tenemos que incluir a Gaspar Becerra, pues entre la fecha aproximada de la comisión del cuadro y la segura presencia del andaluz en España, en diciembre de 1557, no pasaron más de dos años.

Becerra utiliza en los frescos de la Historia de Perseo en el Palacio de El Pardo la citada pintura de Daniele da Volterra. Así, la figura de Mercurio aparece, convenientemente vestida como el héroe en Perseo roba el ojo de las Greas (fig. 17), y en la Decapitación de Medusa,

\footnotetext{
${ }^{35}$ La capilla fue concedida a Lucrezia della Rovere en agosto de 1548, y el mismo día se comprometió a decorarla; en enero de 1553 se estimaban las pinturas ejecutadas hasta entonces, que se consideran terminadas hacia 1560. Según Pugliatti se produjo una interrupción en los trabajos a cusa de la muerte de la comitente, lo que explicaría la estimación de la capilla, todavía inacabada en 1553. Pugliatti, op., cit., pp. 65-69. Agradezco la colaboración de Adriano Luzzi, director de la restauración de la capilla, y del resto de su equipo.

${ }^{36}$ Sobre el pequeño diseño $(17 \times 20 \mathrm{~cm}$.), Jaffé, D.: «Daniele da Volterra and his followers», The Burlington Magazine vol. cxxviii, n. ${ }^{\circ} 996$, marzo 1986, pp. 184-190. También Zezza, A., «Tra Perín del Vaga e Daniele da Volterra: alcune proposte e qualche conferma per Marco Pino a Roma.», Prospettiva, 73-74, 1994, pp. 144-158. Fracchia, aunque sin mencionar el dibujo, destaca la influencia de Marco Pino en el fresco y considera que Becerra utiliza la composición en el retablo de Astorga para representar el Nacimiento de la Virgen, lo que no compartimos; de hecho, ambos tienen en común, como mucho, una lejana inspiración en la pintura del mismo tema de Sebastiano del Piombo en la capilla Chigi de Santa María del Popolo. Fracchia, art., cit., p. 141.

${ }^{37}$ Albers, G. y Morel, Ph.: «Pellegrino Tibaldi e Marco Pino alla Trinità dei Monti», Bolletino d'Arte, 48, 1988 , pp. $69-$ 92.

${ }^{38}$ Voss publicó en 1922 la pintura, hoy perdida y considerada copia del original. Voss, H.: «Ein wiedergefundenes Bild des Daniele da Volterra», Kunstchronik, XXIV, 1922-23, pp. 375-378. Barolsky, P.: Daniele da Volterra. A catalogue raisonné. Londres, 1979, pp. 98-99.

${ }^{30}$ Vasari, op., cit., p. 545. Sobre la fecha de la comisión, véase Campana, L.: «Monsignore Giovanni della Casa e i suoi tempi, vita privata», Studi storici, XVII (1908), p. 389.

${ }^{413}$ El inventario de Fulvio Orsini en de Nolhac, P.: «Les collections de Fulvio Orsini», Gazette des Beaux Arts, XXIX, 1884 , p. $427-436$
} 


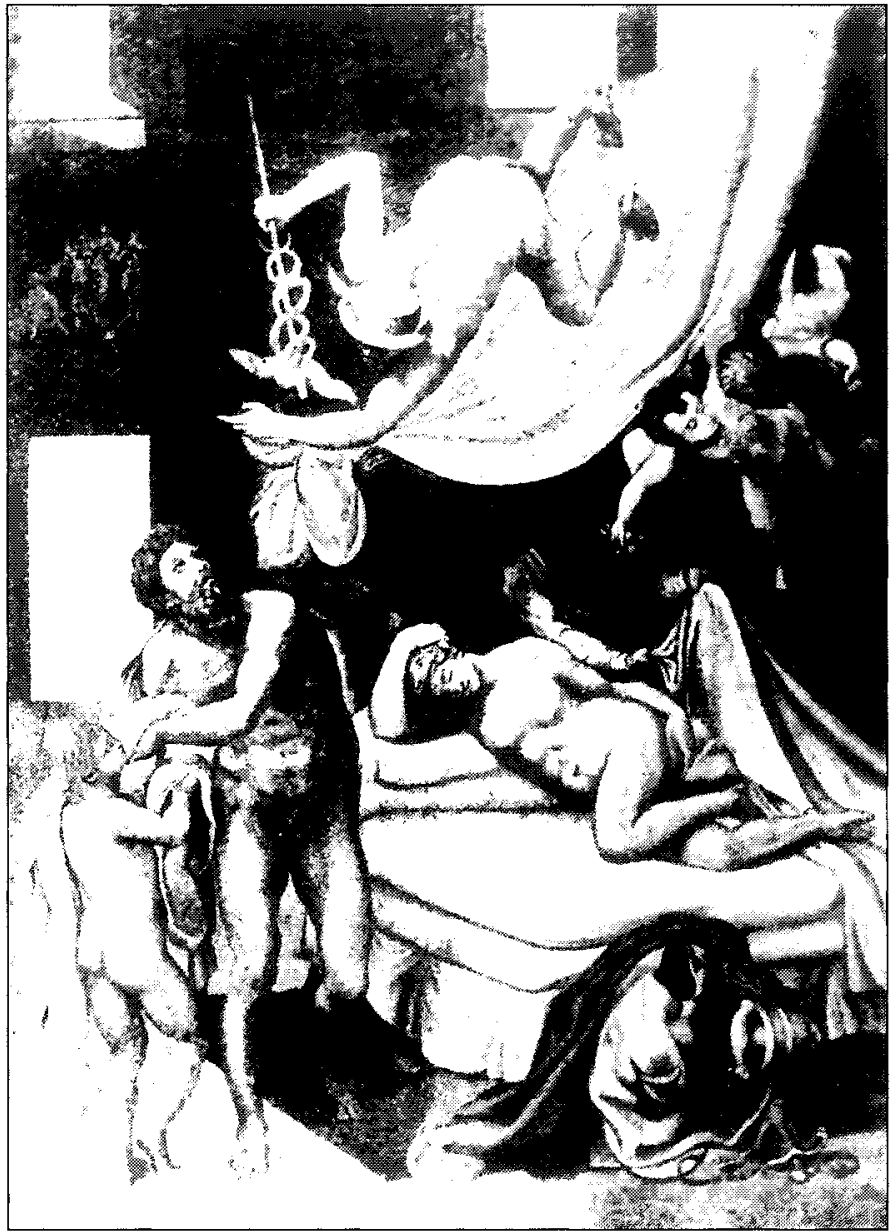

Fig. 16. Daniele da Volterra. Mercurio Ordena a Eneas dejar a Dido. (Desaparecido). aunque dibujada desde otro punto de vista (fig. 18). El andaluz copia también la figura de Dido, de la que se conoce un dibujo y una escultura ${ }^{41}$, siempre de Daniele da Volterra, que sirve de modelo para la representación de Medusa, parcialmente cubierta, en el ciclo de El Pardo. Aunque la cita no es tan precisa como la de Mercurio, la minuciosidad con la que se ha ejecutado el torso sugiere que el español conocía, y de primera mano, la pintura, el dibujo, o la escultura del italiano. Hemos mencionado que Becerra representa una misma figura, Mercurio, desde dos puntos de vista diferentes. Probablemente utilizó uno de los pequeños modelos escultóricos en yeso o cera de los que se servía Daniele da Volterra para estudiar las figuras de sus pinturas. Precisamente Giovanni Della Casa encargó al volterrano un pequeño modelo escultórico de David y Goliat del cual se debía realizar una transcripción en pintura que representara el grupo desde dos puntos de vista diferentes, plasmado a am-

bos lados del cuadro, pretendiendo superar así el punto de vista único consentido por la representación pictórica ${ }^{42}$. El cuadro, que sería acompañado de un tratado escrito por Della Casa referente a la primacía de la pintura sobre la escultura, manifiesta claramente la actitud del Daniele da Volterra al respecto, aplicando la respuesta que sobre la cuestión dio Miguel Ángel a Varchi «... la pittura va più tenuta buona quanto più va verso il rilievo, et il rilievo più tenuto cattivo quanto più va verso la pittura», afirmación que matiza el Buonarroti «...a me soleva parere che la scultura fussi la lanterna della pittura, e che da l'una a l'altra fosse la differenza che è dal sole alla luna ... ora poi che io ho letto il vostro libretto (se refiere a Varchi) ... mi son mutato d'opennione e dico che ... la scultura è la pittura è una medesima cosa» ${ }^{43}$.

En la misma línea debemos considerar la actitud de Becerra respecto al Paragone entre la pintura y la escultura, pues en la Decapitación de Medusa en el Palacio de El Pardo, los héroes (estatuas) petrificados por la mirada de la gorgona son copias literales de las figuras de la Capilla Paolina en el Vaticano, últimas pinturas de Miguel Ángel, cuya plástica, difundida en

\footnotetext{
"' Sobre el dibujo y la escultura, véase Joannides, P.: «Daniele da Volterra’s Dido», Burlington Magazine, vol. CXXXV, n. . 1089, diciembre 1993, pp. 818-819.

42 Vasari, op., cit., p. 545.

${ }^{4.3}$ El texto en Barocchi, P.: Scritti d'arte del Cinquecento, vol. III. Milán, 1978, pp. 522-523.
}

$A E A, \mathrm{LXXV}, 2002,298$, pp. 129 a 144 


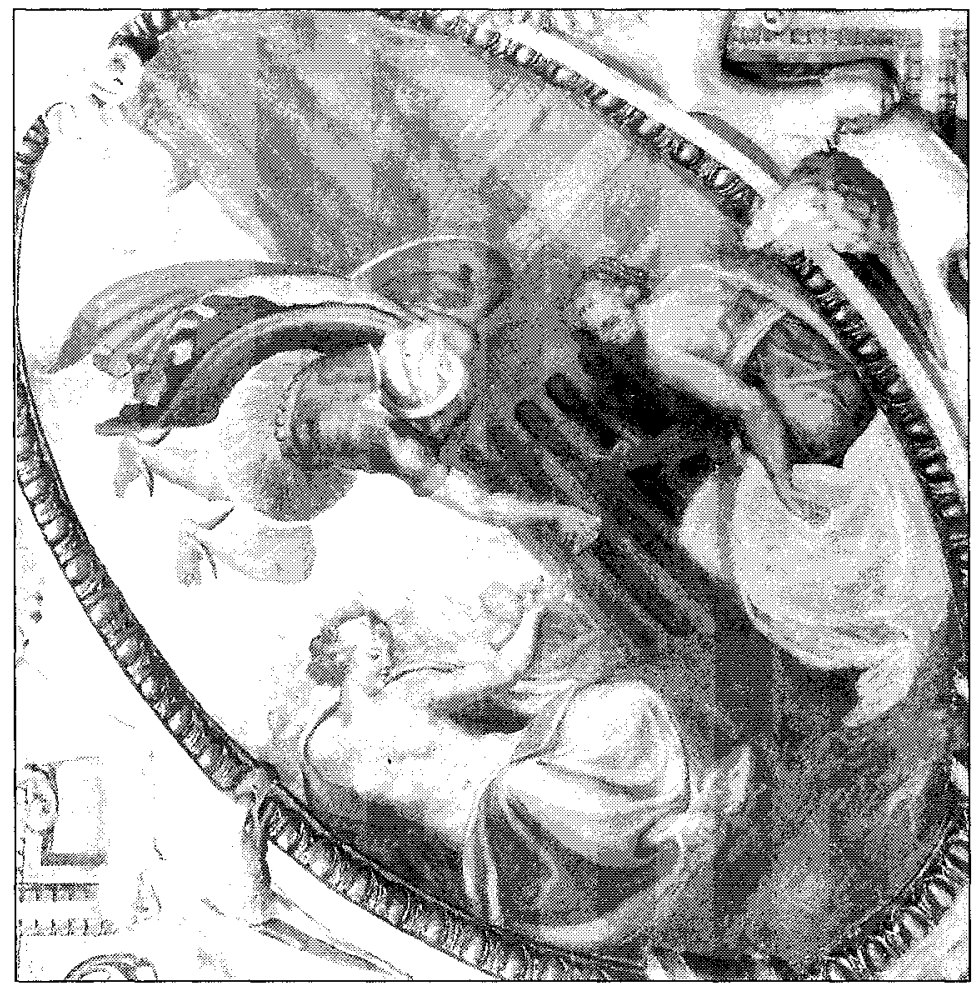

17

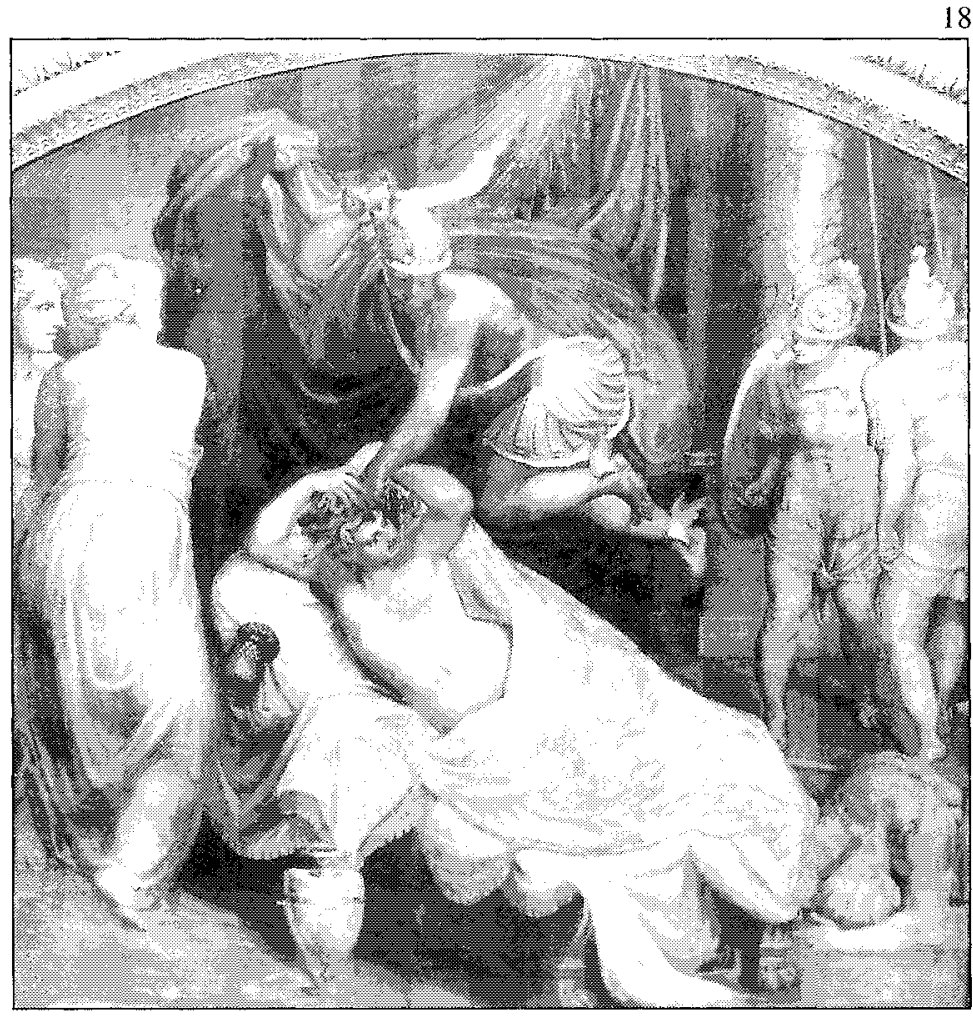

Fig. 17. Palacio de El Pardo. Perseo roba el ojo de las Greas. Patrimonio Nacional, neg. C98C58D Fig. 18. Decapitación de Medusa. Palacio de El Pardo. Patrimonio Nacional, neg. C98C58D. 
España por Becerra, habría de definir decisivamente la escultura en buena parte de la península en la segunda mitad del siglo xvI.

\section{Apéndice documental}

(1) Contrato entre Constantino del Castillo y Gaspar Becerra para la capilla de la Asunción en Santiago de los Españoles. Archivio Storico Capitolino. Archivio Urbano. Sez. I. Leg. 269. ff.197 y 197 v. 28 de agosto 1553. Notario Biagio de Casarruvias.

Oy este dia se han concordado el muy magnifico señor Constantino del Castillo dean de Cuenca y Gaspar Becerra, estante en Roma, maestro de pintura, sobre la obra y pintura que se ha de hacer en la capilla que el dicho señor dean tiene en Santiago de los españoles en el principio de la nave que esta a mano derecha como se entra por la puerta principal que responde a la estrada maestra donde está la sapienza o estudio. In primis un quadro principal de altar, el qual ha de ser de leño llamado albucio de buena madera que convenga dentro pintada la ystoria de la asuntion de Nuestra señora ornada de figuras con los doze apostoles y lo demás como conviene a tal ystoria pintada a olio de colores buenas y recipientes. La cornice del dicho quadro ha de ser de estuco y dorada y entallada de entallos que se requieren a tal obra y los dichos entallos sean de endorar en aquellas partes donde mas conviniente fuera a la dicha obra que haga favor al dicho ornamento y a de ser astante en la pared de la dicha capilla. Ytem la luneta, medio redondo que viene encima del dicho quadro [a redondo] a de ser pintada en fresco donde viene dios padre y el hijo y el spiritu santo con la corona, que encoronan a nuestra señora que sea pintada en fresco de colores buenas como conviene a la tal obra. Ytem que la corniz que responde al dicho redondo corresponda a aquella del quadro de de (sic) abaxo y sea de estuco y [entallada de oro] metida a oro en las partes que convenga. Ytem todo el arco con los pilastres sean adornados de estuco como en el debuxo se muestra, entallado y tocado de oro en las partes mas convenientes, ansimismo la corniz de travertino sea cubierta de estuco y entallada y tocada de oro en las partes convenientes. Ytem en los cantones de dicho arco sobre el alquitrave dos figuras, conviene a saber, el angel y nuestra señora, que es la anunciada, con el spiritu sancti pintada en fresco. En la mitad del dicho arco el arma del dicho señor dean con aquella grandeza que convenga adornada de estuco y tocada a oro como se requiere a tal obra y con su epitafio. Ytem el quadro que viene sobre el arco en el que ha de aver la ystoria como nuestro Señor parece a nuestra Señora resucitado con aquellos santos padres y animas que salieron del linbo y unos angeles encima en el ayre con un rotulo que diga regina celi letare est, a de ser pintada en fresco en el muro de buenas colores como se requiere y el ornamento del dicho quadro ha de ser de estuco metido a oro en las partes convenientes como en el debuxo se muestra. Ytem en el ornamento que viene sobre el dicho quadro ha de ser de figuras de relievo de estuco donde a de aver tres figuras con lo demas como pareciere al maestro con su ornamento entallado y metido de oro donde de requiere como conviene. Ytem encima del dicho redondo un espicho de la buelta ha de ser pintado de fresco en el muro con las colores convinientes con la ystoria de la cruz que se a hallado y de santa Elena que la muestra a Constantino emperador con los otros ornamentos y figuras que parecera al maestro y de la una parte la fïgura y retrato del dicho señor dean con unas doncellas detrás que van dotadas para casarse. Ytem que toda la dicha obra ha de ser en toda perficion a vista de y juyzio de maestros del arte, la qual obra el dicho Gaspar Becerra la ha de hazer a toda su espesa ansi de cal, porcelana, maestro (sic), pinturas, oro, leñames y todo lo necessario que fuere dentro de doze meses comenzando el primero de setiembre deste presente año a toda su costa como dicho es, y que pasados los doze meses que el dicho señor dean no sea obligado a pagarle mas dineros de los que oviere recivido aunque la obra que hubiere hecho merezca mas la pueda hazer acabar a otro maestro que el quisiere a espesa y daño del dicho Gaspar Becerra excepto enfermedad o muerte [que en tal caso se este a juyzio] y el dicho señor dean promete dar al dicho Gaspar Becerra toda la madera que fuere necessaria para las puentes y para cubrir que no puedan entrar allí a darle fastidio contra la voluntad suya. La qual toda obra el dicho Gaspar Becerra se convinió hazerla como dicho es por prezo de dozientos y setenta y cinco scudos de moneda pagados desta manera, que cada mes reciba la gruesa que rendiere el officio de escritoria apostolica cada mes comenzando a recibir la gruesa de de ese mes de agosto, la qual se paga en fin de mes, como es de costumbre, y de ay en adelante, en fin de cada mes, como es de costumbre y lo que quedare de cobrar en fin de los dichos doze meses que el dicho señor dean sea obligado, seyendo acabada la dicha obra en perfición como arriba se dice, pagarlos al dicho Gaspar Becerra o a quien por el tuviere poder para recibirlos realmente y con efeto dentro de un mes despues de los dichos doze meses, para lo qual se obligan etc. en forma de la camara apostolica (..) a xxviii de agosto 1553 .

AEA, LXXV, 2002, 298, pp. 129 a 144 